\title{
Cytokine production by dendritic cells genetically engineered to express IL-4: induction of Th2 responses and differential regulation of IL-12 and IL-23 synthesis
}

Yoshitaka Morita ${ }^{3}$

Raj Gupta ${ }^{1}$

Kelly M. Seidl ${ }^{1}$

Kevin T. McDonagh ${ }^{2}$

David A. Fox ${ }^{1 *}$

${ }^{1}$ Division of Rheumatology, Department of Internal Medicine, and Rheumatic Disease Core Center, University of Michigan, Ann Arbor, MI, USA

${ }^{2}$ Division of Hematology and Oncology, Department of Internal Medicine, and Rheumatic Disease Core Center, University of Michigan, Ann Arbor, MI, USA

${ }^{3}$ Division of Nephrology and Rheumatology, Department of Internal Medicine, Kawasaki Medical School, Kurashiki, Japan

*Correspondence to: David A. Fox, Division of Rheumatology, University of Michigan, 5520 MSRB I, 1150 W. Medical Center Dr., Ann Arbor, MI 48109, USA.

E-mail: dfox@umich.edu

Received: 14 September 2004 Revised: 19 November 2004 Accepted: 24 November 2004

\begin{abstract}
Dendritic cells (DCs) retrovirally transduced with IL-4 have recently been shown to inhibit murine collagen-induced arthritis and associated Th1 immune responses in vivo, but the mechanisms that underly these effects are not yet understood. In this report we demonstrate that IL-4-transduced DCs loaded with antigen led to lower T cell production of IFN- $\gamma$, increased production of IL-4, and an attenuated, delayed type hypersensitivity response. We hypothesized that the ability of such DCs to regulate the Th1 immune response in vivo depends in part on their capacity to produce IL-12 and IL-23. Quantitative mRNA analysis revealed that IL-4-transduced DCs stimulated with CD40 ligand expressed higher levels of IL-12p35 mRNA, but lower levels of mRNA for IL-23p19 and the common subunit p40 found in both IL-12 and IL-23, compared with control DCs. These results, which indicate that expression of the IL- 12 and IL- 23 subunits is differentially regulated in IL-4-transduced DCs, were confirmed by ELISA of the IL-12 and IL-23 heterodimers. Thus, therapeutic suppression of Th1 -mediated autoimmunity (as recently shown in murine collagen-induced arthritis) and induction of Th2 responses in vivo by IL-4-transduced DCs occurs despite their potential to produce increased levels of IL-12, but could reflect, in part, decreased production of IL-23. Copyright $\odot 2005$ John Wiley \& Sons, Ltd.
\end{abstract}

Keywords dendritic cells; cytokines; collagen-induced arthritis; immune response; autoimmunity

\section{Introduction}

Dendritic cells (DCs) are potent APCs in the induction and the regulation of immune responses [1]. Recently, attention has been focused on the use of DCs in immunotherapy. We previously demonstrated that a single injection of bone-marrow-derived DCs retrovirally transduced to express IL4 reduces the incidence and severity of murine collagen-induced arthritis (CIA), a model of rheumatoid arthritis [2]. Since IL-4-transduced polyclonal $\mathrm{T}$ cells or fibroblastic cells failed to inhibit CIA, the ability of IL-4-transduced DCs to inhibit the ongoing pathogenic Th1 response may require specific interaction between T cells and IL-4-secreting DCs [2]. A second group also showed suppression of CIA using DCs infected with an adenoviral vector that expressed IL-4 [3]. Further studies are necessary, however, to fully understand the functional characteristics of these engineered cells. 
IL-12, one of the important immunoregulatory cytokines secreted by DCs, is a $70-\mathrm{kD}$ disulfide-linked heterodimer of p35 and p40 subunits that was originally described as a factor that stimulates both natural killer (NK) cell and cytotoxic T cell activity [4,5]. It is now clear that IL-12 has a pivotal role in promoting Th1-type immune responses by inducing differentiation of naive $\mathrm{T}$ cells into the Th1 phenotype [6-8]. Furthermore, IL-12 augments the established Th1 response by inducing T cell proliferation and IFN- $\gamma$ production [9-12]. IL-23, a more recently identified cytokine expressed by DCs, that may also be pivotal in the activation of T cells, has both structural and functional similarities to IL-12. It is composed of the IL-12p40 subunit and a novel p19 protein [13]. IL23 induces proliferation and IFN $-\gamma$ production by $\mathrm{T}$ cells [13]. Although IL-23 may play an important role in the induction of Th1 responses, it does not bind to IL- $12 \mathrm{R} \beta 2$ [13], and may therefore have a role distinct from IL-12 in the differentiation of $\mathrm{T}$ cells.

The major stimuli known to elicit IL-12 or IL-23 production by DCs are the ligation of CD40 by the CD40 ligand (CD40L, CD154) expressed on activated T cells, and binding of bacterial products to specific DC surface receptors [13-15]. Previous studies have documented conflicting results regarding the regulatory effect of IL4 on the ability of DCs to produce IL-12; IL-4 was initially reported to be inhibitory [15], but more recent studies demonstrate that it can enhance IL-12 production [16-18]. Most of these studies do not include data on the expression of individual IL-12 subunits, and did not measure expression of the IL-23p19 subunit. Since the ability of IL-4-expressing DCs to regulate the immune response may be affected in part by altered production of IL-12 and/or IL-23, we investigated the effect of retroviral transduction of DCs with IL-4 on production of these cytokines.

The potential of IL-4-transduced primary culture DCs to skew antigen-specific immune responses in primary immune reactions has not yet been determined. Our previous studies demonstrated that IL-4-transduced DCs alter the balance of Th1/Th2 cells in the spleen, and cause a shift toward a polyclonal Th2 response [2]; we therefore hypothesized that immunization with IL-4transduced DCs pulsed with antigen could induce primary Th2 immune responses.

\section{Materials and methods}

\section{Mice}

Male C57BL/6 mice were purchased from the Jackson Laboratory (Bar Harbor, ME, USA) and used at 8-10 weeks of age. Animal use procedures were approved by the University of Michigan Committee on the Use and Care of Animals.

\section{Culture medium for DCs}

Complete medium (CM) consisted of RPMI 1640 supplemented with $10 \%$ heat-inactivated fetal calf serum (FCS), $0.1 \mathrm{mM}$ nonessential amino acids, $1 \mathrm{mM}$ sodium pyruvate, $2 \mathrm{mM}$ L-glutamine, $100 \mathrm{U} / \mathrm{ml}$ penicillin, $100 \mu \mathrm{g} / \mathrm{ml}$ streptomycin, and $5 \times 10^{-5} \mathrm{M} 2$-ME (all from Life Technologies, Grand Island, NY, USA).

\section{Generation of bone-marrow-derived DCs}

DCs were obtained from a 5 day culture of bone marrow (BM) cells in $10 \mathrm{ng} / \mathrm{ml}$ recombinant murine GM-CSF (Immunex, Seattle, WA, USA) and $10 \mathrm{ng} / \mathrm{ml} \mathrm{rmIL-4}$ (Schering-Plough, Kenilworth, NJ, USA) as described [19]. DCs were enriched by centrifugation on $14.5 \%$ metrizamide (Sigma, St. Louis, MO, USA) gradients and washed in HBSS, generating a cell population of more than $90 \%$ DCs by immunophenotypic analysis [19].

\section{Generation of retrovirally transduced DCs from BM cells}

IL-4- or enhanced green fluorescent protein (EGFP)transduced DCs were generated as described [2]. Based on measurement of EGFP expression by flow cytometry, more than $90 \%$ of DCs were consistently transduced [2]. IL-4-transduced DCs produced $10-50$ ng IL-4/10 6 cells per $24 \mathrm{~h}$ as defined by ELISA. IL-4 was not detected in the culture supernatants of EGFP-transduced DCs.

\section{In vivo anti-keyhole limpet hemocyanin (KLH) response}

EGFP- or IL-4-transduced DCs were cultured overnight in CM with or without $50 \mu \mathrm{g} / \mathrm{ml}$ of $\mathrm{KLH}$. The DCs were washed in HBSS and $2 \times 10^{5}$ cells were injected subcutaneously (s.c.) in the right and left thighs of mice. Inguinal lymph nodes were harvested 5 days after DC injection. Lymph node cells were resuspended in Click's medium (Life Technologies) supplemented with $1 \%$ heatinactivated mouse serum, and $5 \times 10^{5}$ cells were cultured with or without KLH $(50 \mu \mathrm{g} / \mathrm{ml})$ in 96 -well flat-bottomed plates. Culture supernatants were assayed by ELISA for IL-2 after $48 \mathrm{~h}$, and for IFN- $\gamma$, IL-4, and IL-10 after $72 \mathrm{~h}$.

\section{Delayed type hypersensitivity (DTH) assay}

EGFP- or IL-4-transduced DCs were pulsed with $50 \mu \mathrm{g} / \mathrm{ml}$ KLH overnight. After extensive washing, the KLH-pulsed DCs $\left(2 \times 10^{5}\right)$ were injected s.c. into the right flanks of mice. Eight days later, these animals were challenged by s.c. injection of KLH $(25 \mu \mathrm{g} / 10 \mu$ l phosphate-buffered saline (PBS)) into the right hind footpad. The same volume of PBS alone was injected into the left hind footpad as a control. Footpad swelling responses were 
measured at $24 \mathrm{~h}$ by a blinded observer using a caliper with consistent pressure (Mitutoyo, Aurora, IL, USA). The response was calculated as the difference between the right and left footpad swelling.

\section{Cytokine assays}

Murine IFN- $\gamma$, IL-2, IL-4, IL-10, IL-12p70, p40, and IL18 were assayed by ELISA using paired antibodies (Abs) (BD PharMingen, San Diego, CA, USA) according to the manufacturer's instructions. Mouse IL-23 was measured by ELISA using antibody and IL-23 standards generously supplied by Dr. Robert Kastelein (DNAX), as previously described [13].

\section{Preparation of a mouse CD40L- transfected NIH 3T3 cell line}

A cDNA encoding murine CD40L was obtained from pNGVL3-mCD40L (Vector Core, Center for Gene Therapy, University of Michigan) and subcloned into the pRET6 retroviral vector [2]. The Phoenix A amphotropic packaging cell line (provided by G. Nolan, Stanford University, Palo Alto, CA, USA) was transiently transfected with the pRET6-mCD40L construct using calcium/phosphate precipitation. The ecotropic GP + E86 packaging cell line [20] was subsequently infected with filtered viral supernatants from Phoenix A in the presence of protamine sulfate. A polyclonal ecotropic producer line was established by selection with puromycin $(4 \mu \mathrm{g} / \mathrm{ml})$. Murine fibroblast NIH 3T3 cells were transduced with filtered retroviral supernatants from GP + E86-mCD40L and selected with puromycin $(4 \mu \mathrm{g} / \mathrm{ml})$ for 3 days. Cell surface expression of CD40L was confirmed by flow cytometry.

\section{Culture of DCs}

DCs were incubated in 12-well plates at a density of $10^{6} / \mathrm{ml}$ with rmCD40L-trimer $(10 \mu \mathrm{g} / \mathrm{ml}$, Immunex $)$, lipopolysaccharide (LPS) $(1 \mu \mathrm{g} / \mathrm{ml})$, or LPS plus IFN- $\gamma$ (1000 U/ml, Life Technologies) in the presence or absence of rmIL-4 (10-50 ng/ml) or rmIL-10 (50 ng/ml), both from R\&D Systems (Minneapolis, MN, USA). To neutralize IL-4, anti-IL-4 mAb (20 $\mu \mathrm{g} / \mathrm{ml}, 11 \mathrm{~B} 11$, BD PharMingen $)$ was added to some cultures. In some experiments, DCs were co-cultured in 12-well plates with irradiated (30 Gy) mouse CD40L-transfected NIH 3T3 cells plated overnight at $2.35 \times 10^{5}$ cells/well. Culture supernatants were harvested at $6-48 \mathrm{~h}$ and stored at $-80 \mathrm{C}$ until analyses. For mRNA analysis, cells were lysed in Trizol after 6 or 12 h of culture.

\section{Semiquantitative RT-PCR}

Total cellular RNA was extracted with Trizol in a single-step method, and used for the synthesis of firststrand cDNA with oligo- $(\mathrm{dT})_{15}$ and reverse transcriptase (Life Technologies). cDNA samples were amplified using Taq polymerase (Promega, Madison, WI, USA) in a thermal cycler (Perkin-Elmer, Norwalk, CT, USA). Reaction products were analyzed by electrophoresis and visualized by ethidium bromide staining. cDNA (1-3 $\mu \mathrm{l})$ from serially diluted samples was amplified for 26 cycles using primers for hypoxanthine phosphoribosyl transferase (HPRT), and the amount of PCR product was determined by densitometric analysis and plotted against the sample volume. The amplification of cDNA was linear in the range of the sample volumes that were used. cDNA concentrations of each sample were normalized to yield equivalent HPRT polymerase chain reaction (PCR) products. The appropriate PCR cycles were established for semiquantitative assay of each individual PCR product; 26 cycles for $\mathrm{p} 40,32$ cycles for $\mathrm{p} 19$, and 36 cycles for p35. The PCR primers used for HPRT, p35, and p40 were described by Kato et al. [21]. The following primers were used for p19: 5'-GCTGTTGCCCTGGGTCACTCA-3' and 5'-CTGGGCATCTGTTGGGTCTCC-3'

\section{Real-time PCR}

Real-time PCR was performed using the iCycler iQ detection system (Bio-Rad Laboratories, Hercules, CA, USA) with a dual-labeled fluorogenic probe. The primers and probes used (Table 1) were obtained from Life Technologies and Integrated DNA Technologies (Coralville, IA, USA), respectively. The probes for $\mathrm{p} 35$, p19, and p40 were labeled with 6-FAM and BHQ-1, and the $\gamma$-actin probe was labeled with HEX and BHQ1. Reactions were performed in duplicate in a 96-well iCycler iQ PCR plate (Bio-Rad Laboratories) in $50 \mu \mathrm{l}$ of total reaction volumes with $1.5 \mathrm{U}$ Platinum Taq DNA polymerase (Life Technologies), $4 \mathrm{mM} \mathrm{MgCl}_{2}, 200 \mu \mathrm{M}$ dATP, $200 \mu \mathrm{M}$ dCTP, $200 \mu \mathrm{M}$ dGTP, $400 \mu \mathrm{M}$ dUTP, 1 $\mathrm{U}$ uracil DNA glycosylase, $0.2 \mu \mathrm{M}$ of primer and probe sets for $\mathrm{p} 35, \mathrm{p} 19, \mathrm{p} 40$, or $\gamma$-actin, and cDNA samples. The PCR was performed as follows: one 2 min cycle at $50{ }^{\circ} \mathrm{C}$; one $3 \mathrm{~min}$ cycle at $95^{\circ} \mathrm{C}$; followed by 45 cycles of denaturation for $15 \mathrm{~s}$ at $95^{\circ} \mathrm{C}$ and an annealing/extension step of $1 \mathrm{~min}$ at $60^{\circ} \mathrm{C}$. The threshold cycle is the PCR cycle at which an increase in the fluorescent emission above the baseline signal is first detected. Since the values of the threshold cycle decrease proportionally with increased target quantity, they were used to determine the relative cDNA amounts in each sample and evaluate levels of p35, p19, and p40 mRNA which were normalized by the quantity of $\gamma$-actin mRNA.

\section{Results}

\section{In vivo primary immune reactions induced by adoptive transfer of KLH-pulsed IL-4-transduced DCs}

To examine the potential of IL-4-transduced DCs to skew cytokine production in primary immune reactions, EGFP- 
Table 1. Primers and probes used for real-time PCR

\begin{tabular}{llll}
\hline Target gene & \multicolumn{1}{c}{ Forward primer } & \multicolumn{1}{c}{ Reverse primer } & \multicolumn{1}{c}{ Probe } \\
\hline IL-12p35 & CACCCTTGCCCTCCTAAACC & CAAGGCACAGGGTCATCATC & (6FAM)CCTCAGTTGGGCCAGGGTCATTCCA (BHQ1) \\
IL-23p19 & CCAGCAGCTCTCTCGGAATC & TCATATGTCCCGCTGGTGC & (6FAM)TGCATGCTAGCCTGGAACGCACA(BHQ1) \\
p40 & TCAGTGCCTGCCAGGAGG & CAGTCAATGGGCAGGGTC & (6FAM)TGTCACCTGCCCAACTGCCGAG(BHQ1) \\
$\gamma$-actin & CGCAAAGACCTGTATGCCAAT & GGGCTGTGATCTCCTCTGC & (HEX)TACCACCATGTACCCAGGCATTGCTGAC(BHQ1) \\
\hline
\end{tabular}

or IL-4-transduced DCs pulsed with KLH were injected s.c. into mice. Inguinal lymph nodes were harvested 5 days later. Lymph node cells were cultured with or without KLH and the culture supernatants were assayed for IFN- $\gamma$, IL-2, IL-4, and IL-10 (Figure 1). Lymph node cells from mice injected with non-pulsed DCs did not secrete lymphokines upon in vitro restimulation with KLH. EGFP-transduced DCs pulsed with KLH induced the activation of cells secreting IFN- $\gamma$, IL-2, IL-4 and IL-10, while IL-4-transduced DC favored the development of T cells producing lower levels of IFN- $\gamma$ and generally less
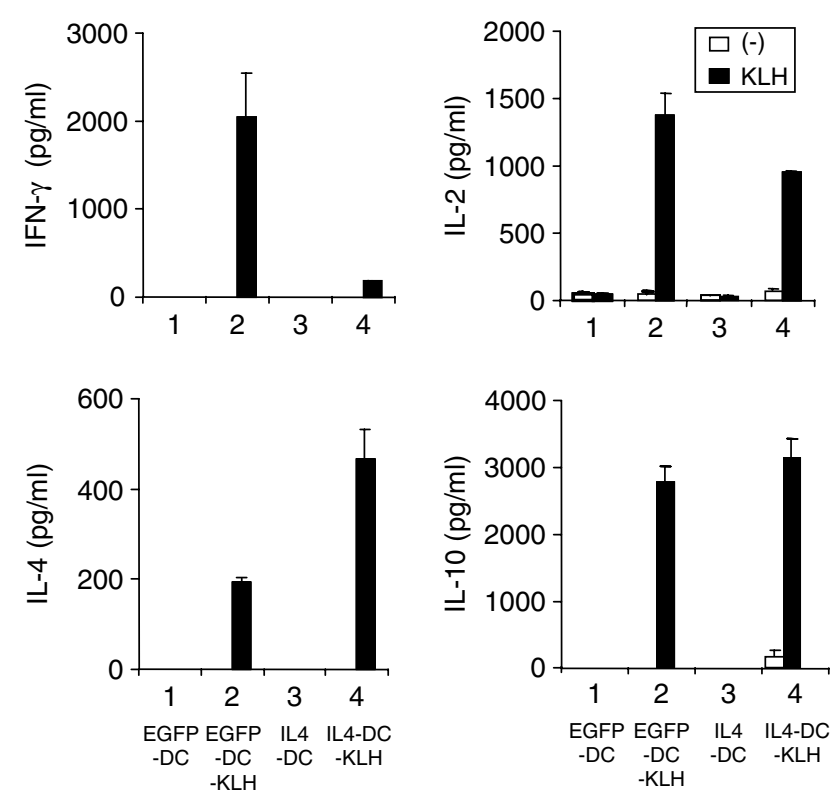

Figure 1. T cell cytokine production by lymph node cells from mice immunized with EGFP- or IL-4-transduced DCs. The transduced DCs were incubated overnight with or without KLH $(50 \mu \mathrm{g} / \mathrm{ml})$. The s.c. injection was performed in the right and left thighs of mice with $2 \times 10^{5}$ cells, respectively. Five days later, inguinal lymph nodes were harvested and cultured with (shaded bars) or without KLH $(50 \mu \mathrm{g} / \mathrm{ml})$. Culture supernatants were assayed by ELISA for IL-2 after $48 \mathrm{~h}$, and IFN- $\gamma$, IL- 4 and IL-10 after $72 \mathrm{~h}$ of incubation. Data are the mean \pm SEM of duplicate cultures. Lane 1, non-pulsed EGFP-transduced DCs; lane 2, KLH-pulsed EGFP-transduced DCs; lane 3, non-pulsed IL-4-transduced DCs; lane 4, KLH-pulsed IL-4-transduced DCs

IL-2, but significantly increased levels of IL-4. These data indicate that IL-4-transduced DCs favor the development of a Th2 response in primary immune reactions in lymph node cells. To examine whether the observed ex vivo cytokine secretion pattern reflects the functional immune response in vivo, a delayed type hypersensitivity (DTH) assay was performed. Eight days after injection of KLHpulsed DCs, mice were rechallenged and examined for footpad swelling responses to KLH. The extent of swelling induced in animals that had received IL-4-transduced DCs was approximately $50 \%$ of that seen with EGFPtransduced DCs (Figure 2).

\section{IL-4 increases IL-12 heterodimer and decreases $\mathrm{p} 40$ production by BM-derived DCs}

We next examined the effect of IL-4 on production of the heterodimeric IL-12p70 and the p40 subunit by bone marrow (BM)-derived DCs, as determined by ELISA of culture supernatants (Table 2). In these experiments, BM-derived DCs were stimulated for 12 or $24 \mathrm{~h}$ through Tcell-dependent (rmCD40L-trimer) or T-cell-independent (LPS) pathways in the presence or absence of IL-4. IL12 p70 levels were significantly increased by IL-4 in the context of stimulation by either LPS or CD40L. In contrast, p40 levels were decreased.

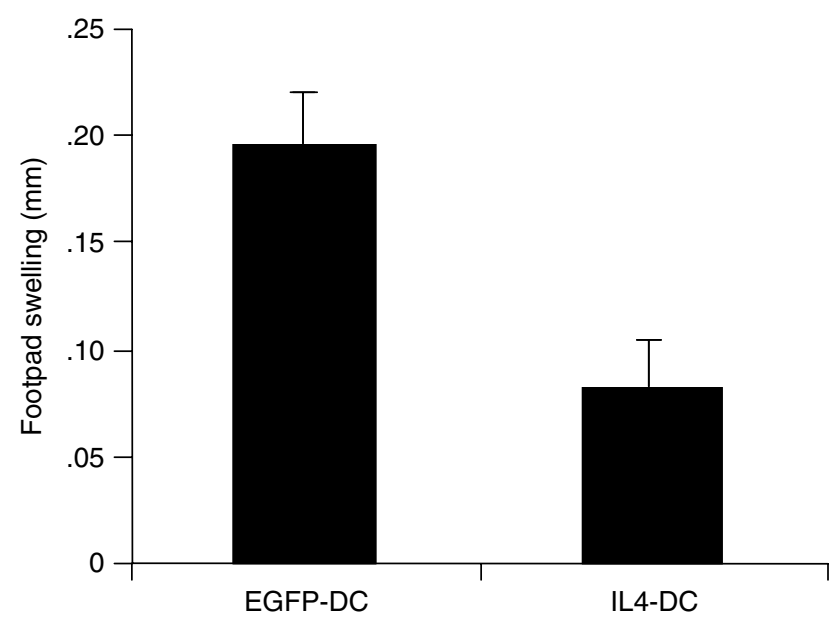

Figure 2. DTH responses induced by EGFP- or IL-4-transduced DCs. KLH-pulsed EGFP- or IL-4-transduced DCs $\left(2 \times 10^{5}\right)$ were injected s.c. into the right flanks of mice. Eight days later, these animals were challenged by s.c. injection of $\mathrm{KLH}(25 \mu \mathrm{g} / 10 \mu \mathrm{l}$ PBS) into the right hind footpad, or PBS into the left hind footpad. The response was calculated as the difference between the right and left footpad swelling. Data are the mean \pm SEM of five individual mice/group. The footpad swelling induced by IL-4-transduced DCs was significantly $(p<0.05)$ diminished compared with that induced by EGFP-transduced DCs 
Table 2. Effect of IL-4 on the production of IL-12p70 and p40 production by bone-marrow-derived DCs

\begin{tabular}{|c|c|c|c|c|c|c|c|c|c|}
\hline & & \multicolumn{2}{|c|}{$(-)$} & \multicolumn{2}{|c|}{ CD40L } & \multicolumn{2}{|c|}{ LPS } & \multicolumn{2}{|c|}{ LPS + IFN- $\gamma$} \\
\hline & & $(-)$ & $+\mathrm{IL}-4$ & $(-)$ & $+\mathrm{IL}-4$ & $(-)$ & $+\mathrm{IL}-4$ & $(-)$ & $+\mathrm{IL}-4$ \\
\hline \multirow[t]{2}{*}{ IL-12p70 (pg/ml) } & $12 \mathrm{~h}$ & $<20$ & $<20$ & $<20$ & 120 & 517 & 1690 & 1750 & 5690 \\
\hline & $24 \mathrm{~h}$ & $<20$ & $<20$ & $<20$ & 123 & 314 & 1330 & 1770 & 5900 \\
\hline \multirow[t]{2}{*}{ p40 (ng/ml) } & $12 \mathrm{~h}$ & 0.4 & 0.3 & 4.0 & 1.7 & 30.8 & 14.9 & 57.5 & 24.3 \\
\hline & $24 \mathrm{~h}$ & 1.8 & 0.6 & 7.0 & 2.2 & 27.6 & 14.6 & 58.5 & 40.4 \\
\hline
\end{tabular}

DCs $\left(10^{6} / \mathrm{ml}\right)$ were cultured for 12 or $24 \mathrm{~h}$ with $\mathrm{rmCD} 40 \mathrm{~L}-$ trimer $(10 \mu \mathrm{g} / \mathrm{ml})$, LPS $(1 \mu \mathrm{g} / \mathrm{ml})$ or LPS plus IFN- $\gamma(1000 \mathrm{U} / \mathrm{ml})$ in the presence of absence of IL-4 $(50 \mathrm{ng} / \mathrm{ml})$. Concentrations of IL-12p70 and p40 in the culture supernatants were measured in duplicate by ELISA. The data shown are from a single experiment representative of two identical experiments.

\section{IL-4 differentially regulates IL-12 and IL-23 subunit gene expression in BM-derived DCs}

To directly examine the effect of IL-4 on expression of IL-12 and IL-23 subunit genes in BM-derived DCs, the mRNA levels of IL-12p35, IL-23p19, and the common subunit p40 were assessed by PCR (Figures 3A and 3B). p35 mRNA expression was enhanced by the combination of CD40 ligation and IL-4, but this enhancement was inhibited by IL-10 at $12 \mathrm{~h}$. In contrast, p19 and p40 mRNA expression was induced by CD40L alone, but this induced expression was decreased by IL-4 or IL-10. To confirm the semiquantitative PCR results, p35, p19, and p40 mRNA expression was also determined by real-time PCR using different sets of primers and a different house keeping gene, $\gamma$-actin, and similar results were obtained (Figure 3C). When comparing the results at 6 and $12 \mathrm{~h}$, it is evident that induction of p35 mRNA is more sustained when DCs are stimulated by CD40L in the presence of IL-4.

\section{Increased production of IL-12p70 in IL-4-transduced DCs}

We next evaluated the effect of retroviral transduction of DCs with IL-4 on production of IL-12p70 and p40 by the transduced DCs. EGFP- or IL-4-transduced DCs were stimulated for $24 \mathrm{~h}$ by rmCD40L-trimer, LPS, or LPS plus IFN- $\gamma$ and levels of cytokines in culture supernatants were determined by ELISA (Table 3). The results were similar to the findings observed in untransduced DCs exposed to IL-4. IL-12p70 levels were significantly increased in IL-4-transduced DCs by both LPS and CD40L stimuli, compared with EGFP-transduced DCs. By contrast, p40 levels tended to be lower in culture supernatants of IL-4transduced DCs, especially after the CD40L stimulus. We also measured IL-18, which could be produced by DCs, and may play a role for Th1/Th2 immune responses [22]. IL-18 was not detected in the culture supernatants of DCs. When CD40L-transfected cells were used as the CD40L stimulus, similar results were obtained (Figure 4A). To confirm the specificity of the effect of IL-4 on the transduced DCs, EGFP-transduced DCs were cultured for $24 \mathrm{~h}$ with various concentrations of rmIL-4 in the presence
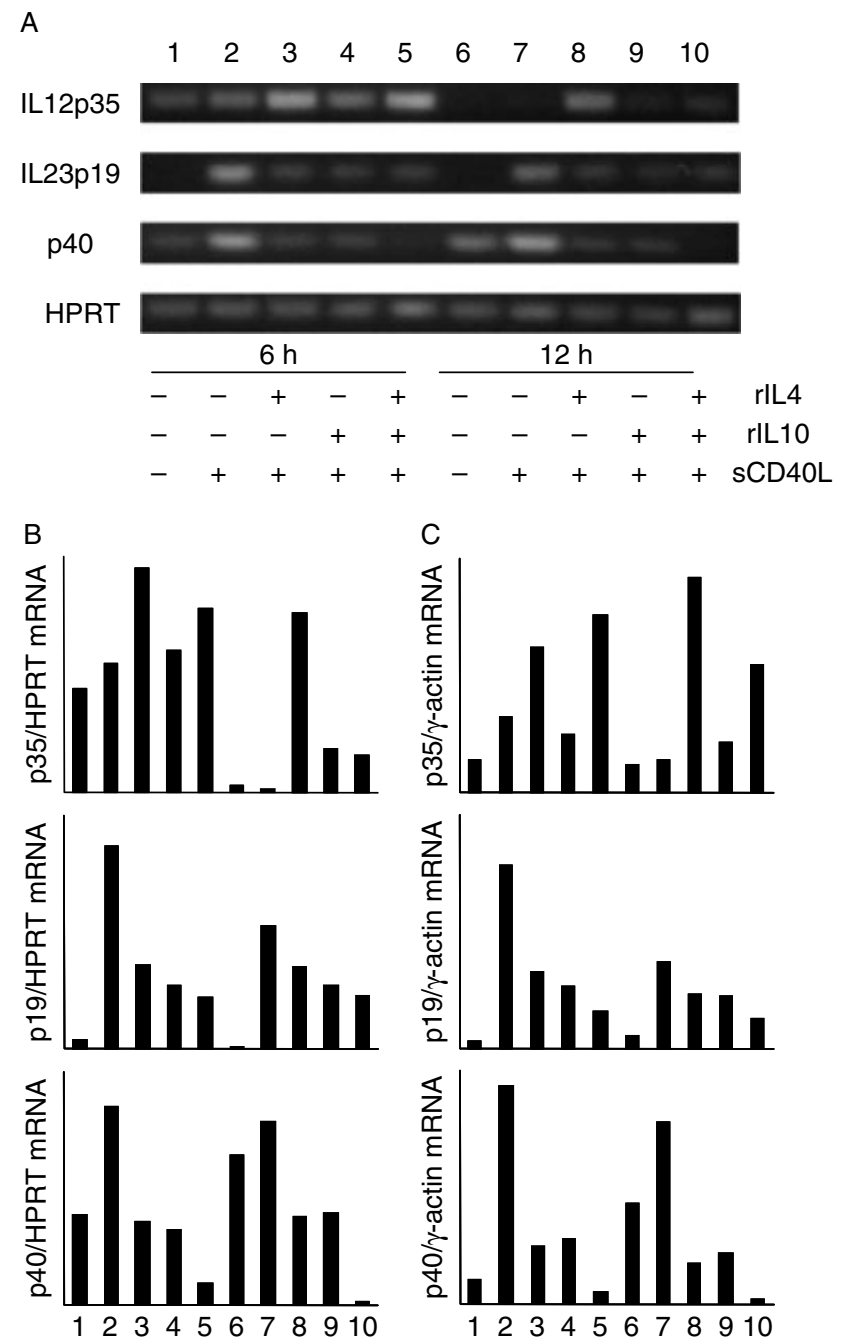

Figure 3. Effects of IL-4 and IL-10 on the expression of mRNA for IL-12 and IL-23 subunits in bone-marrow-derived DCs. DCs $\left(10^{6} / \mathrm{ml}\right)$ were stimulated for $6 \mathrm{~h}$ (lanes $\left.1-5\right)$ or $12 \mathrm{~h}$ (lanes 6-10) with rmCD40L-trimer $(10 \mu \mathrm{g} / \mathrm{ml})$ and IL-4 $(50 \mathrm{ng} / \mathrm{ml})$ or IL-10 (50 ng/ml) as follows: lanes 1 and 6, control; lanes 2 and 7, CD40L; lanes 3 and 8, CD40L and IL-4; lanes 4 and 9, CD40L and IL-10; lanes 5 and 10, CD40L, IL-4, and IL-10. (A, B) mRNA expression of IL-12p35, IL-23p19, and the common subunit p40 were measured by semiquantitative RT-PCR. (A) PCR products were stained with ethidium bromide. (B) Data were obtained from densitometric analysis, and all values were further normalized by HPRT PCR product. (C) Real-time PCR was performed as described in 'Materials and methods'. Levels of p35, p19, or p40 mRNA were normalized to $\gamma$-actin mRNA level. The $y$-axis in (B) and (C) corresponds to a scale of arbitrary units 
Table 3. IL-12p70 and p40 production by EGFP- or IL-4-transduced DCs

\begin{tabular}{|c|c|c|c|c|c|c|c|c|}
\hline & \multicolumn{2}{|c|}{$(-)$} & \multicolumn{2}{|c|}{ CD40L } & \multicolumn{2}{|c|}{ LPS } & \multicolumn{2}{|c|}{$\mathrm{LPS}+\mathrm{IFN}-\gamma$} \\
\hline & EGFP-DC & IL4-DC & EGFP-DC & IL4-DC & EGFP-DC & IL4-DC & EGFP-DC & IL4-DC \\
\hline $\begin{array}{l}\text { IL-12p70 (pg/ml) } \\
\text { p40 (ng/ml) }\end{array}$ & $\begin{array}{r}<20 \\
0.6\end{array}$ & $\begin{array}{l}<20 \\
0.6\end{array}$ & $\begin{array}{l}30 \\
6.3\end{array}$ & $\begin{array}{l}600 \\
4.2\end{array}$ & $\begin{array}{l}150 \\
37.3\end{array}$ & $\begin{array}{r}2280 \\
25.6\end{array}$ & $\begin{array}{c}1630 \\
63.7\end{array}$ & $\begin{array}{r}7070 \\
53.1\end{array}$ \\
\hline
\end{tabular}

Virally transduced DCs $\left(10^{6} / \mathrm{ml}\right)$ were cultured for $24 \mathrm{~h}$ with or without $\mathrm{rmCD} 40 \mathrm{~L}$-trimer $(10 \mu \mathrm{g} / \mathrm{ml})$, LPS $(1 \mu \mathrm{g} / \mathrm{ml})$ or LPS plus IFN- $\gamma(1000 \mathrm{U} / \mathrm{ml})$. Culture supernatants were assayed in duplicate for cytokines by ELISA. The data shown are from a single experiment representative of five identical experiments.

of CD40L-transfected cells, and IL-12p70 and p40 levels in culture supernatants were determined by ELISA (Figure 4B). The results revealed that rmIL-4 augmented IL-12p70 production, but diminished p40 production in a dose-dependent manner. Additionally, when IL-4transduced DCs were cultured with neutralizing antiIL-4 mAb, IL-12p70 production was decreased and p40 production was increased (Figure $4 \mathrm{~B}$ ).

\section{Differential gene expression of IL-12 and IL-23 subunits in EGFP- or IL-4-transduced DCs}

We also determined mRNA levels of p35, p19, and p40 in EGFP- or IL-4-transduced DCs treated with rmCD40Ltrimer and assessed by both semiquantitative RT-PCR and real-time PCR (Figure 5). As expected, p35, p19, and p40 mRNA expression by transduced DCs was induced by the CD40L stimulus. IL-4-transduced DCs expressed higher levels of p35 mRNA but lower levels of p19 and p40 mRNA, compared with EGFP-transduced DCs.

\section{Exposure to IL-4 during activation of DCs suppresses IL-23 secretion}

To confirm that IL-4 could directly and specifically suppress production of IL-23, BM-derived DCs were cultured on 3T3 cells that express CD40L, and $48 \mathrm{~h}$ culture supernatants were assayed for the IL-23 heterodimer by ELISA. IL-4 at 10 or $50 \mathrm{ng} / \mathrm{ml}$ substantially suppressed IL23 production, an effect that was prevented by inclusion of neutralizing anti-IL-4 $\mathrm{mAb}$ in the culture medium (Figure 6).

\section{Discussion}

We previously reported that DCs genetically engineered to express IL-4 inhibit established Th1 responses in an experimental model of autoimmune arthritis [2]. Expression of MHC molecules and co-stimulatory ligands for $\mathrm{T}$ cell activation was not affected by IL4 gene transduction, but splenic $\mathrm{T}$ cell production of IL-4 in response to anti-CD3 was enhanced after administration of IL-4-transduced DCs [2]. The present study further examines the functional characteristics of
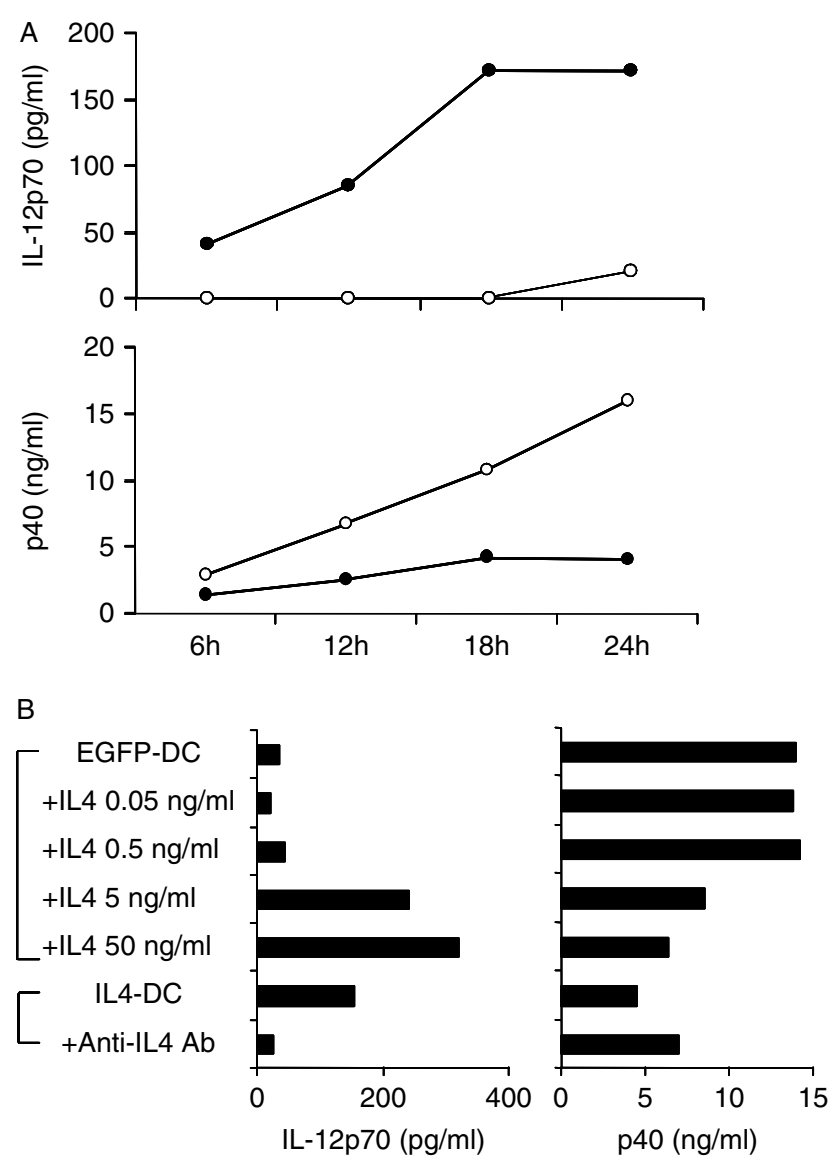

Figure 4. Effect of IL-4 on the production of IL-12p70 and p40 by retrovirally transduced DCs. (A) EGFP- or IL-4-transduced DCs $\left(10^{6} / \mathrm{ml}\right)$ were co-cultured for the indicated time with CD40L-expressing NIH 3T3 cell lines. Closed circles, IL-4- transduced DCs; open circles, EGFP-transduced DCs. (B) EGFP-transduced cells were co-cultured for $24 \mathrm{~h}$ with CD40L-expressing cells in the presence of the indicated concentrations of rmIL-4. IL-4-transduced cells were co-cultured with CD40L-expressing cells in the presence or absence of neutralizing anti-IL-4 mAb. Concentrations of IL-12p70 and p40 in culture supernatants were measured in duplicate by ELISA

these unique cells. We hypothesized that immunization with antigen-pulsed IL-4-transduced DCs could induce Th2 responses in vivo in primary immune responses. This study supports that hypothesis since KLH-pulsed IL-4transduced DCs preferentially induced the activation of $\mathrm{T}$ cells programmed to secrete IL-4. Moreover, DTH reaction induced by IL-4-transduced DCs is significantly reduced compared with that seen with control DCs. This change 
A
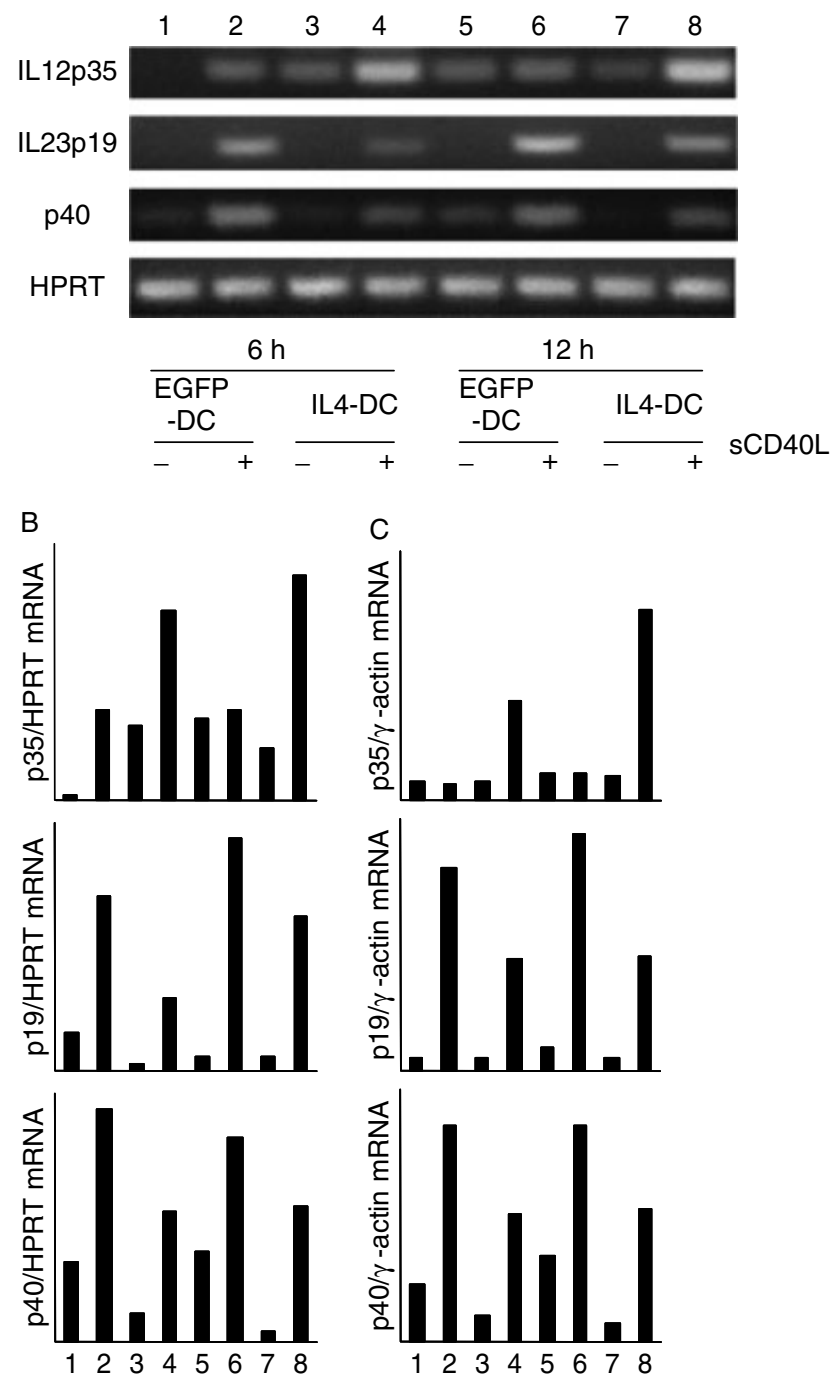

Figure 5. Differential mRNA expression of IL-12 and IL-23 subunits in EGFP- or IL-4-transduced DCs. The transduced DCs $\left(10^{6} / \mathrm{ml}\right)$ were stimulated for $6 \mathrm{~h}$ (lanes $\left.1-4\right)$ or $12 \mathrm{~h}$ (lanes 5-8) with rmCD40L-trimer $(10 \mu \mathrm{g} / \mathrm{ml})$. RNA was extracted from cultures of EGFP-transduced DCs without stimulus (lanes 1 and 5) or with CD40L (lanes 2 and 6), and from cultures of IL-4-transduced DCs without stimulus (lanes 3 and 7) or with CD40L (lanes 4 and 8). (A, B) mRNA expression of IL-12p35, IL-23p19, and p40 was measured by semiquantitative RT-PCR. (A) PCR products were stained with ethidium bromide. (B) Data obtained from densitometric analysis are shown and all values were normalized by HPRT PCR product. (C) Real-time PCR was performed and levels of p35, p19, or p40 mRNA were normalized to $\gamma$-actin mRNA level. Data is displayed as described in Figure 1

in the strength of the DTH response may reflect downregulation of the secretion of $\gamma$-IFN by IL- 4 and/or other regulatory mechanisms.

Cytokine production is one of the most important mechanisms by which DCs determine the direction of $\mathrm{T}$ cell immune responses, and DC-derived IL-12 is critical for induction of primary Th1 immune responses [22-25]. Injection of distinct subsets of DCs, pulsed with antigen, preferentially induces Th1 or Th2 responses in mice, in a pattern that is clearly associated with their capacity

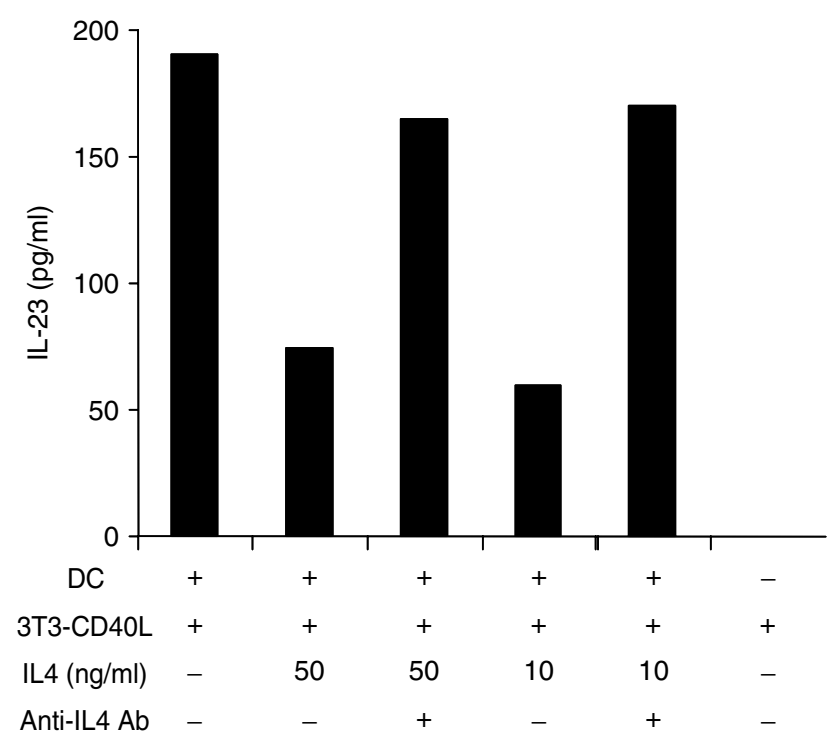

Figure 6. IL-4 inhibits IL-23 release by DCs. DCs were co-cultured for $48 \mathrm{~h}$ with CD40L-expressing NIH 3T3 cell lines in the presence of the indicated concentrations of rmIL-4, and in the presence or absence of neutralizing anti-IL-4 mAb. Concentrations of IL-23 heterodimer in culture supernatants were measured in duplicate by ELISA

to secrete IL-12 in vitro [23-25]. Distinct subsets of human DCs, DC1 or DC2, which have different capacities to produce IL-12, induce the in vitro differentiation of naive $\mathrm{T}$ cells into Th1 or Th2 cells, respectively [26]. Previous studies have demonstrated the role of IL-4 in the regulation of IL-12 production by activated DCs [15-18]. Initial work documented an inhibitory effect of IL-4 on the production of IL-12 by mouse splenic DCs stimulated by anti-CD40 mAb [15]. However, more recent work has demonstrated that IL-4 enhances IL-12 production by mouse splenic DCs treated with various stimuli [16], and by cultured human monocyte-derived DCs stimulated with CD40L [16-18]. During initial stages of DC activation by infectious agents in vivo, IL-4 induction of DC IL-12 production may help to initiate Th1 responses, while later in the course of T cell priming IL-4 induces a Th2 response [27]. We focused on bone marrow (BM)-derived DCs, since their use for immunotherapeutic approaches is being explored. Our data supports these recent results by demonstrating that IL-4 strongly increases secretion of IL-12p70 by mouse BM-derived DCs, either untransduced or retrovirally transduced, in response to CD40 ligation or LPS.

Semiquantitative and quantitative mRNA analyses clearly show that expression of the IL-12 and IL-23 subunits is differentially regulated by $\mathrm{IL}-4$ for each subunit. The data from semiquantitative and real-time PCR assays yielded very similar results in this regard, despite some minor quantitative differences. Our results demonstrate that (1) IL-4 up-regulates IL-12p35 mRNA expression in DCs in the presence of a CD40L stimulus; (2) CD40 ligation induces expression of both IL-23p19 and the common subunit p40 mRNA, and both of them are down-regulated by IL-4; (3) IL-10 inhibits p40 
mRNA expression. Considering that IL-4 enhances IL12 p70 production and the $\mathrm{p} 40$ subunit is more abundant than IL-12p70, p35 expression is therefore the limiting factor controlling production of IL-12p70 by DCs. This conclusion is consistent with results observed in another APC, human monocytes, stimulated with LPS [28,29].

IL-4-expressing DCs induced Th2 responses in lymph node $\mathrm{T}$ cells that were exposed to antigen in vivo, and, in our previous study, inhibited arthritis in the CIA model [2]. It is of particular interest that both of these effects occurred despite the potential of IL-4 DCs to produce increased levels of IL-12. It has been thought that IL-4 is dominant over IL-12 for effects on T cell differentiation, since addition of IL- 4 and IL-12 together induces Th2 development in vitro using T cells from a TCR-transgenic mouse [6]. Our data suggest a dominant effect of IL-4 in vivo, but could also reflect decreased production of IL23. Since IL-4 down-regulates mRNA expression of both p19 and p40 subunits that form IL-23, we hypothesized that IL-4 directly decreases the production of IL-23 by DCs, and confirmed this by ELISA. IL-23 is known to stimulate IFN- $\gamma$ production by $\mathrm{T}$ cells [13]. If DCderived IL-23 cooperates with IL-12 in the development of Th1 responses, the stimulatory effect of IL- 4 on IL-12 production may be offset by its inhibitory effect on IL-23 production.

Recent reports have suggested that IL-12 is not always required for generation of $\mathrm{Th} 1$ responses, as long as IL-23 is present [30,31]. In a murine EAE model, p35 $-/-$ mice remained susceptible to CNS inflammation, but IL-23-deficient mice were resistant [32]. Direct proinflammatory effects of IL-23 on macrophage function were demonstrated, as well as effects on generation and function of Th1 memory cells [32]. Moreover, although both IL-12 and IL-23 also act on DCs themselves, their effects on DC function are distinct, with IL-23 uniquely able to shift the outcome of antigen presentation from tolerance to immunogenicity [33]. The effects of IL-23 are mediated through the IL-23 receptor, which includes IL-12 $\mathrm{R} \beta 1$ as well as a distinct IL-23R subunit [34]. Transgenic overexpression of IL-23 p19 leads to a fatal, multi-organ inflammatory process [35]. In human psoriasis, IL-23 is expressed more strongly than IL-12 by lesional cutaneous DCs [36]. IL-23 has been reported to markedly up-regulate $\mathrm{T}$ cell production of the pro-inflammatory cytokine IL-17, an effect not duplicated by IL-12 [37]. Taken together, these reports emphasize that IL-23 may have a dominant role in initiating Th1 immune responses and related inflammatory pathways. This notion is consistent with our present findings that DC IL-12 and IL-23 gene expression and cytokine production respond in a divergent manner to regulation by IL-4. This differential regulation of IL-12 and IL- 23 by IL- 4 could be unique to DCs, since IL4 coordinately down-regulated both IL-12 and IL-23 in virus-activated macrophages [38].

In some systems it can be shown that priming of IFN- $\gamma$ producers still occurs in the presence of both IL-4 and IL12 , although IFN- $\gamma$ production is inhibited by the presence of IL-4 [8]. Indeed, our results show that IL-4-transduced
DCs still induce a DTH response, although its magnitude is significantly diminished compared with responses induced by control DCs. Therefore, DC-derived IL-12 may limit the ability of IL-4-transduced DCs to control Th1-mediated autoimmune diseases. Suppression of IL-12 production in IL-4-transduced DCs might result in more potent immunoregulatory effects. Further modification of DCs, such as treatment with aspirin [39] or with IL-10 [40], or transduction with both IL-4 and IL-10, could be considered.

In summary, this report provides additional information regarding the functional profile of IL-4-transduced DCs. Our findings show that IL-4-expressing DCs induce Th2 responses not only in the CIA model, but also in primary antigen-specific immune responses. Our data also indicate a distinct regulatory role of IL-4 in the differential expression of IL- 12 and IL- 23 by DCs. Therefore, the mode of action of IL-4 in vivo may be more complex than previously appreciated, encompassing the influence of IL4 on APCs, including DCs, as well as on T cells. Supporting this notion, some Th1-type inflammatory diseases can be exacerbated by IL-4 treatment $[41,42]$, and DCs transduced with an adenoviral IL-4 construct accelerated allograft rejection [43]. Furthermore, defective Th1 responses were recently demonstrated in IL-4-deficient mice $[44,45]$. Further understanding of DC biology and the immunoregulatory roles of cytokines such as IL-4, IL-10, IL-12, and IL-23 will be necessary for rational use of cytokine-modified DCs for human disease.

\section{Acknowledgements}

This work was supported by research grants from the Wilson Foundation and the Arthritis Foundation (to Y.M. and D.A.F.), by Grant-in-Aid for Young Scientists from The Ministry of Education, Culture, Sports, Science and Technology, Japan (15790512 to Y.M.), by Research Project Grants from Kawasaki Medical School (16-413F to Y.M.), by National Institutes of Health grants (DK02349 to K.T.M. and AR38477 to D.A.F.), and by the University of Michigan Rheumatic Disease Core Center. We thank Dr. Michael B. Widmer of Immunex for rmGM-CSF and rmCD40L-trimer, Dr. Robert Kastelein of DNAX for the IL-23 ELISA reagents, Jennifer Fuller for her work in preparing the pRET6-mCD40L construct, Dr. Nobuhiro Takeshita and Judith Endres for technical assistance, and Dr. Ekaphop Sirachainan and Sutang Guo for help with real-time PCR assays.

\section{References}

1. Banchereau J, Steinman RM. Dendritic cells and the control of immunity. Nature 1998; 392: 245-252.

2. Morita Y, Yang J, Gupta R, et al. Dendritic cells genetically engineered to express IL-4 inhibit murine collagen-induced arthritis. J Clin Invest 2001; 107: 1275-1284.

3. Kim SH, Kim S, Evans CH, et al. Effective treatment of established murine collagen-induced arthritis by systemic administration of dendritic cells genetically modified to express IL-4. J Immunol 2001; 166: 3499-3505.

4. Kobayashi M, Fitz L, Ryan M, et al. Identification and purification of natural killer cell stimulatory factor (NKSF), a cytokine with multiple biologic effects on human lymphocytes. $J$ Exp Med 1989; 170: 827-845. 
5. Stern AS, Podlaski FJ, Hulmes JD, et al. Purification to homogeneity and partial characterization of cytotoxic lymphocyte maturation factor from human B-lymphoblastoid cells. Proc Natl Acad Sci U S A 1990; 87: 6808-6812.

6. Hsieh CS, Macatonia SE, Tripp CS, et al. Development of TH1 CD4+ $\mathrm{T}$ cells through IL-12 produced by Listeria-induced macrophages. Science 1993; 260: 547-549.

7. Manetti R, Parronchi P, Giudizi MG, et al. Natural killer cell stimulatory factor (interleukin 12 [IL-12]) induces T helper type 1 (Th1)-specific immune responses and inhibits the development of IL-4-producing Th cells. J Exp Med 1993; 177: 1199-1204.

8. Seder RA, Gazzinelli R, Sher A, et al. Interleukin 12 acts directly on CD4+ T cells to enhance priming for interferon gamma production and diminishes interleukin 4 inhibition of such priming. Proc Natl Acad Sci U S A 1993; 90: 10 188-10 192.

9. Gately MK, Desai BB, Wolitzky AG, et al. Regulation of human lymphocyte proliferation by a heterodimeric cytokine, IL-12 (cytotoxic lymphocyte maturation factor). J Immunol 1991; 147: 874-882.

10. Chan SH, Perussia B, Gupta JW, et al. Induction of interferon gamma production by natural killer cell stimulatory factor: characterization of the responder cells and synergy with other inducers. J Exp Med 1991; 173: 869-879.

11. Sieling PA, Wang XH, Gately MK, et al. IL-12 regulates T helper type 1 cytokine responses in human infectious disease. $J$ Immunol 1994; 153: 3639-3647.

12. Morita Y, Yamamura M, Nishida K, et al. Expression of interleukin-12 in synovial tissue from patients with rheumatoid arthritis. Arthritis Rheum 1998; 41: 306-314.

13. Oppmann B, Lesley R, Blom B, et al. Novel p19 protein engages IL-12p40 to form a cytokine, IL-23, with biological activities similar as well as distinct from IL-12. Immunity 2000; 13: $715-725$.

14. Cella M, Scheidegger D, Palmer-Lehmann K, et al. Ligation of CD40 on dendritic cells triggers production of high levels of interleukin-12 and enhances $\mathrm{T}$ cell stimulatory capacity: T-T help via APC activation. J Exp Med 1996; 184: 747-752.

15. Koch F, Stanzl U, Jennewein P, et al. High level IL-12 production by murine dendritic cells: upregulation via MHC class II and CD40 molecules and downregulation by IL-4 and IL-10. J Exp Med 1996; 184: 741-746.

16. Hochrein H, O'Keeffe M, Luft T, et al. Interleukin (IL)-4 is a major regulatory cytokine governing bioactive IL-12 production by mouse and human dendritic cells. J Exp Med 2000; 192: 823-833.

17. Ebner S, Ratzinger G, Krosbacher B, et al. Production of IL-12 by human monocyte-derived dendritic cells is optimal when the stimulus is given at the onset of maturation, and is further enhanced by IL-4. J Immunol 2001; 166: 633-641.

18. Kalinski P, Smits HH, Schuitemaker JH, et al. IL-4 is a mediator of IL-12p70 induction by human Th2 cells: reversal of polarized Th2 phenotype by dendritic cells. J Immunol 2000; 165: 1877-1881.

19. Fields RC, Shimizu K, Mule JJ. Murine dendritic cells pulsed with whole tumor lysates mediate potent antitumor immune responses in vitro and in vivo. Proc Natl Acad Sci U S A 1998; 95: 9482-9487.

20. Markowitz D, Goff S, Bank A. A safe packaging line for gene transfer: separating viral genes on two different plasmids. $J$ Virol 1988; 62: 1120-1124.

21. Kato $T$, Hakamada $R$, Yamane $H$, et al. Induction of IL-12 p40 messenger RNA expression and IL-12 production of macrophages via CD40-CD40 ligand interaction. $J$ Immunol 1996; 156: 3932-3938.

22. Stoll S, Jonuleit H, Schmitt E, et al. Production of functional IL-18 by different subtypes of murine and human dendritic cells (DC): DC-derived IL-18 enhances IL-12-dependent Th1 development. Eur J Immunol 1998; 28: 3231-3239.

23. Pulendran B, Smith JL, Caspary G, et al. Distinct dendritic cell subsets differentially regulate the class of immune response in vivo. Proc Natl Acad Sci U S A 1999; 96: 1036-1041.

24. Maldonado-Lopez R, De Smedt T, Michel P, et al. CD8alpha+ and CD8alpha- subclasses of dendritic cells direct the development of distinct T helper cells in vivo. J Exp Med 1999; 189: 587-592.

25. Iwasaki A, Kelsall BL. Freshly isolated Peyer's patch, but not spleen, dendritic cells produce interleukin 10 and induce the differentiation of T helper type 2 cells. $J$ Exp Med 1999; 190: 229-239.

26. Rissoan MC, Soumelis V, Kadowaki N, et al. Reciprocal control of T helper cell and dendritic cell differentiation. Science 1999; 283: 1183-1186.

27. Biedermann T, Zimmermann S, Himmelrich H, et al. IL-4 instructs TH1 responses and resistance to Leishmania major in susceptible BALB/c mice. Nat Immunol 2001; 2: 1054-1060.

28. Hayes MP, Wang J, Norcross MA. Regulation of interleukin-12 expression in human monocytes: selective priming by interferongamma of lipopolysaccharide-inducible p35 and p40 genes. Blood 1995; 86: 646-650.

29. Snijders A, Hilkens CM, van der Pouw Kraan TC, et al. Regulation of bioactive IL-12 production in lipopolysaccharidestimulated human monocytes is determined by the expression of the p35 subunit. $J$ Immunol 1996; 156: 1207-1212.

30. Cooper AM, Kipnis A, Turner J, et al. Mice lacking bioactive IL12 can generate protective, antigen-specific cellular responses to mycobacterial infection only if the IL-12 p40 subunit is present. $J$ Immunol 2002; 168: 1322-1327.

31. Gran B, Zhang GX, Yu S, et al. IL-12p35-deficient mice are susceptible to experimental autoimmune encephalomyelitis: evidence for redundancy in the IL-12 system in the induction of central nervous system autoimmune demyelination. $J$ Immunol 2002; 169: 7104-7110.

32. Cua DJ, Sherlock J, Chen Y, et al. Interleukin-23 rather than interleukin-12 is the critical cytokine for autoimmune inflammation of the brain. Nature 2003; 421: 744-748.

33. Belladonna ML, Renauld JC, Bianchi R, et al. IL-23 and IL-12 have overlapping, but distinct, effects on murine dendritic cells. J Immunol 2002; 168: 5448-5454.

34. Parham C, Chirica M, Timans J, et al. A receptor for the heterodimeric cytokine IL-23 is composed of IL-12Rbeta1 and a novel cytokine receptor subunit, IL-23R. J Immunol 2002; 168: 5699-5708.

35. Wiekowski MT, Leach MW, Evans EW, et al. Ubiquitous transgenic expression of the IL-23 subunit p19 induces multiorgan inflammation, runting, infertility, and premature death. J Immunol 2001; 166: 7563-7570.

36. Lee E, Trepicchio WL, Oestreicher JL, et al. Increased expression of interleukin 23 p19 and p40 in lesional skin of patients with psoriasis vulgaris. J Exp Med 2004; 199: 125-130.

37. Aggarwal S, Ghilardi N, Xie MH, et al. Interleukin-23 promotes a distinct CD4 $\mathrm{T}$ cell activation state characterized by the production of interleukin-17. J Biol Chem 2003; 278: 1910-1914.

38. Pirhonen J, Matikainen S, Julkunen I. Regulation of virusinduced IL-12 and IL-23 expression in human macrophages. J Immunol 2002; 169: 5673-5678.

39. Hackstein H, Morelli AE, Larregina AT, et al. Aspirin inhibits in vitro maturation and in vivo immunostimulatory function of murine myeloid dendritic cells. J Immunol 2001; 166: 7053-7062.

40. De Smedt T, Van Mechelen M, De Becker G, et al. Effect of interleukin-10 on dendritic cell maturation and function. Eur $J$ Immunol 1997; 27: 1229-1235.

41. Ramanathan S, de Kozak Y, Saoudi A, et al. Recombinant IL-4 aggravates experimental autoimmune uveoretinitis in rats. $J$ Immunol 1996; 157: 2209-2215.

42. Fort M, Lesley R, Davidson N, et al. IL-4 exacerbates disease in a Th1 cell transfer model of colitis. J Immunol 2001; 166: 2793-2800.

43. Kaneko K, Wang Z, Kim SH, et al. Dendritic cells genetically engineered to express IL-4 exhibit enhanced IL-12p70 production in response to CD40 ligation and accelerate organ allograft rejection. Gene Ther 2003; 10: 143-152.

44. Mencacci A, Del Sero G, Cenci E, et al. Endogenous interleukin 4 is required for development of protective CD4+ T helper type 1 cell responses to Candida albicans. J Exp Med 1998; 187: 307-317.

45. Schuler T, Qin Z, Ibe S, et al. T helper cell type 1-associated and cytotoxic T lymphocyte-mediated tumor immunity is impaired in interleukin 4-deficient mice. J Exp Med 1999; 189: 803-810. 